\title{
Analytic Hierarchy Process-based Social Public Sports Facility Utilization and Development Research
}

\author{
Jianguo Zhu*
}

Nanjing Sport Institute, Nanjing 210014, Jiangsu, China

\begin{abstract}
A great deal of attention has been paid to social public sports facility construction in China. Studies being conducted on China's social public sports facility utilization status have important significance in promotion of national sports investment. In this paper, China's social public sports facility utilization status is analyzed by literature searching method and data statistical analysis method which highlight that Chinese sports facility does not meet people demands, and has imbalanced utilization ratio status. In order to balance the status, the paper utilizes analytic hierarchy process, establishing factor analysis model, and by virtue of MATLAB software, it analyzes the consideration factors on the basis of which people select sports facilities, and also obtains weight of each influence factor. The main factors for consideration are whether sports facility possesses fitness efficiency, is the related equipment complete or not, and whether it has got weight loss efficiency? In the light of these consideration factors, suggestions are also provided for the country in the paper as follows: remove lower utilization ratio of sports facilities in densely populated housing estates and parks; pay particular attention to the sports facilities for old people in housing estates and to district level national fitness activity center construction; focus on the maintenance of old sports facilities .
\end{abstract}

Keywords: Analytic hierarchy process, Factor analysis model, MATLAB software, Social public sports, Sports facility.

\section{INTRODUCTION}

With comprehensive development of China's social economy, its government has begun to put more emphasis on public sports development. The outline of the twelfth five year plan has clearly put forward the idea stating "improve people's health levels; develop sports undertakings and sports industry." It is required that both urban and rural basic levels are strengthened in each area and sports facility construction in each school is promoted for further future improvement on a large scale.

Public sports facility is an important carrier of comprehensive urban functions, and also a major part of modern urban construction. Public sports facility planning and construction is a way for implementing national fitness plan, improving national physique and health status, and is an indispensable guarantee condition that propels to spiritual and social civilization. It should be taken into consideration that public sports facility meets the demands of residents' organizing sports activities having an account of sports leisure and various other related aspects [1].

With constantly improving living standards, people pay more attention to the development of their physical health. Many people prefer going to fitness venues for physical exercises in their spare time. In addition,- the inspirational hosting of Beijing Olympic Games has greatly aroused people's passion for sports.

Since "National fitness regulations" was released in Oct. 1st, 2009, Chinese sports has entered into a state of rapid

*Address correspondence to this author at the Nanjing Sport Institute, Nanjing 210014, Jiangsu, China; Tel: +86-13770343770;

E-mail: 13770343770@sina.com.cn development [2]. In recent years, China government has constantly increased investments in sports construction. Until August, 2008, China had already invested 6.4 hundred million Yuan to support construction of "Peasants' sports fitness project"; input sports lottery public welfare fund is nearly 1.64 hundred million Yuan, extending input to nearly 27 hundred million Yuan. By the end of 2014, Chinese stateowned sports relative administrative organizations were distributed in 6887 pieces, having a total of 159762 working staff. China has established varieties of public sports facilities that cater to different people. Not only parks, housing estates and sports facilities are everywhere, but there are also indoor public stadiums. In national fitness project, self-service in the name of "national fitness path" has been initiated in 8727 places; "timely help offering project" has been sponsored in 258 places; "peasants' sports fitness project" has also been sponsored in 34361 places. Chinese sports investment and efforts for implementation of sports facility have been largely evident in the recent years [3].

Nation encourages sports development that causes local blindly constructing sports public facility in order to reflect sports development. Sports facility layout and amount distribution are not reasonable which cause people to waste resources on partial sports facility utilization ratio to a certain extent. Presently, with constantly updating living standards, future social sports fitness development is confronted with very high requirements. Considering the problem, the studies on social public sports facilities utilization rate are particularly important [4].

The research on social public sports facility utilization status further discusses national input status of social sports and provides corresponding suggestions. In this way, it not 
only helps the nation to have a better control sports input but also effectively improves current resource utilization rate and avoids wastage of resources.

\section{CHINA PUBLIC SPORTS FACILITY UTILIZA-TION STATUS}

The article utilizes literature searching methods and data statistical analysis method to conduct analysis regarding China's social public sports facilities utilization status.

By gathering information, it has been found out that China's sports facilities construction now is mainly divided into following types:

1) Comprehensive stadium: is equipped with standard track, athletics field, football field;

2) Comprehensive gymnasium: organizes basketball, volleyball, badminton, martial arts and other multiple sports activities and meanwhile it also conducts artistic performance, mass gathering and other cultural activities;

3) Large fitness center: is equipped with table tennis room, multi-function venues (basketball, volleyball, and badminton integration), multi-functional room, and apparatus gym;

4) Natatorium: is equipped with a standard indoor swimming pool and a preparation pool;

5) Sports park: it includes suburb Sports Park, urban sports park, sports facilities having not less than eight items, and out-door exercise-centered area.

Each kind of sports facilities' proportional status is shown in Fig. (1).

China's current public sports field facility is based on a total sum of nearly seven hundred thousand occupying a total area of 78 hundred million $m_{2}$, per capita occupying public sports field of $0.65 \mathrm{~m}_{2}$. However, Chinas' public sports facilities are mostly distributed in campus. Public sports facilities that are distributed in campus are $67.7 \%$ of the totality, which occupy beyond half of the national sports fields facilities. Insofar, it is known that only fewer education system sports fields are open to outsiders, and just $14.9 \%$ is completely open to outsiders. Moreover, campus sports field facilities utilization rate is only $34.7 \%$, which leads to a wastage of campus sports facilities resources.

In China, 13.6 hundred million population that is $22 \%$ school population occupies $66.7 \%$ public sports facilities. If other public sports facilities are all open to outsiders, available public facilities are nearly:

$C=\frac{136000 \times(1-0.22)}{700000 \times(1-0.667)}=4551$ people $/$ piece

Non-students mass per capita occupying public sports field is:

$S=0.65 \times(1-0.22)=0.507 \mathrm{~m}^{2} /$ people

According to China's "Urban social sports facilities construction land indicator" stipulation, China's urban community sports facility graded area indicator is as shown inTable 1:

General administration of sports of China's public sports equipment facility standard is as shown in Table $\mathbf{2}$ :

According to data in Tables $\mathbf{1}$ and 2, compared with formula (1) and (2) results, it can be easily seen that China's sports public facilities quantities demands are far from being fulfilled.

\section{Analytic Hierarchy Process-based Factor Analysis Model Establishment and Solution}

In the investigation process, the paper found out that in public sports facility constructions, a small number of indoor fitness machines causes most people to have the option of going to a professional gym to take physical exercises. In addition, sports facilities local distribution is imbalanced which causes local regional sports facilities tight

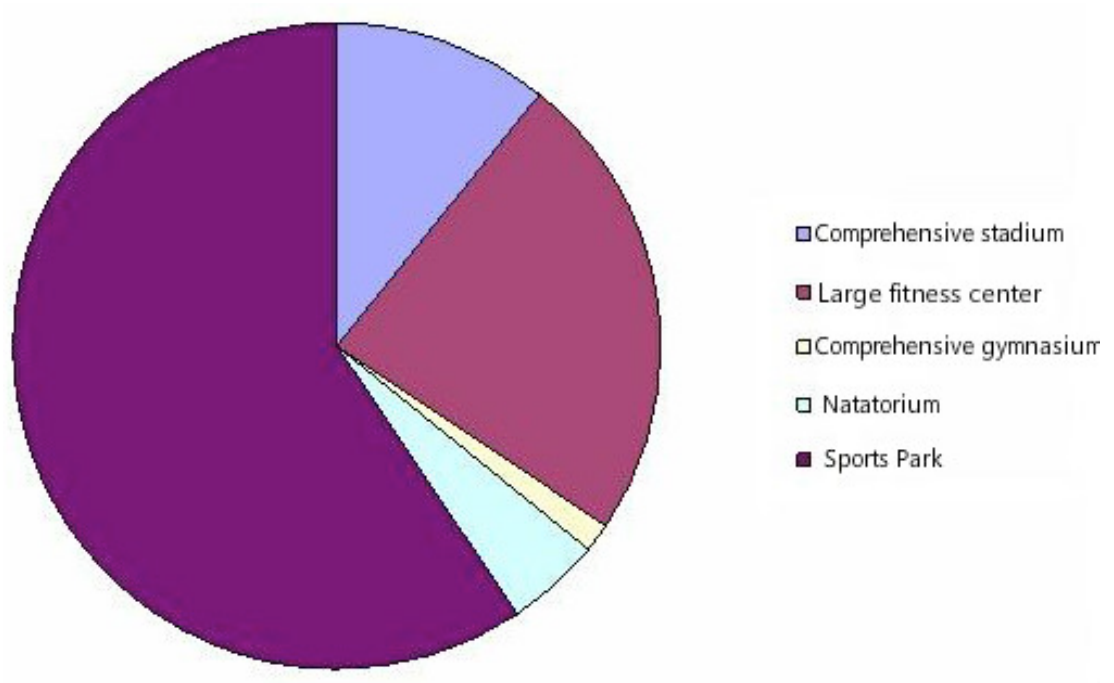

Fig. (1). China public sports facility classification proportion. 
Table 1. China's urban community sports facility graded area indicator.

\begin{tabular}{|c|c|c|}
\hline Population size & Outdoors sports site area $\left(\boldsymbol{m}_{\mathbf{2}}\right)$ & Indoors building area $\left(\boldsymbol{m}_{\mathbf{2}}\right)$ \\
\hline \hline $1000-3000$ & $650-950$ & $170-280$ \\
\hline $10000-15000$ & $4300-6700$ & $2050-2900$ \\
\hline $30000-50000$ & $18900-27800$ & $7700-10700$ \\
\hline
\end{tabular}

Table 2. Public sports equipment facility standard.

\begin{tabular}{|c|c|c|c|c|c|}
\hline & Facility & 1 ten thousand people & 3 ten thousand people & 5 ten thousand people & 10 ten thousand people \\
\hline \multirow{2}{*}{ Outdoors } & Athletics comprehensive field & $\begin{array}{c}1 \text { piece } \\
\left(10000 m_{2}\right)\end{array}$ & $\begin{array}{c}2 \text { pieces } \\
\left(10000 \mathrm{~m}_{2}\right)\end{array}$ & $\begin{array}{c}3 \text { pieces } \\
\left(10000 \mathrm{~m}_{2}\right)\end{array}$ & $\begin{array}{c}6 \text { pieces } \\
\left(10000 m_{2}\right)\end{array}$ \\
\hline & Tennis, volleyball courts & $\begin{array}{l}2 \text { pieces } \\
\left(1560 m_{2}\right)\end{array}$ & $\begin{array}{c}4 \text { pieces } \\
\left(2200 m_{2}\right)\end{array}$ & $\begin{array}{c}6 \text { pieces } \\
\left(2200 m_{2}\right)\end{array}$ & $\begin{array}{l}10 \text { pieces } \\
\left(2840 m_{2}\right)\end{array}$ \\
\hline \multirow{3}{*}{ Indoors } & Basketball, badminton, table tennis fields & $\begin{array}{l}1 \text { piece } \\
\left(720 m_{2}\right)\end{array}$ & $\begin{array}{l}2 \text { pieces } \\
\left(720 m_{2}\right)\end{array}$ & $\begin{array}{l}3 \text { pieces } \\
\left(720 m_{2}\right)\end{array}$ & $\begin{array}{l}5 \text { pieces } \\
\left(720 m_{2}\right)\end{array}$ \\
\hline & Judo kendo & $\begin{array}{c}1 \text { piece } \\
\left(200 m_{2}\right)\end{array}$ & $\begin{array}{l}1 \text { piece } \\
\left(300 m_{2}\right)\end{array}$ & 1 piece $\left(300 m_{2}\right)$ & $\begin{array}{c}1 \text { piece } \\
\left(400 m_{2}\right)\end{array}$ \\
\hline & Swimming pool water area & $\begin{array}{l}1 \text { piece } \\
\left(400 m_{2}\right)\end{array}$ & $\begin{array}{l}2 \text { pieces } \\
\left(400 m_{2}\right)\end{array}$ & $\begin{array}{l}3 \text { pieces } \\
\left(400 m_{2}\right)\end{array}$ & $\begin{array}{l}6 \text { pieces } \\
\left(400 m_{2}\right)\end{array}$ \\
\hline
\end{tabular}

utilization with other regions' public sports facilities utilization rate being low.

In order to boost the input investment, selective construction of public sports facilities is required by letting limited public sports facilities to be used to the maximum . This research study further studied the influence factors that make people select sports facilities.

\section{1) Establish hierarchical structure:}

The interviews of different groups of people have made it clear that when people select sports facilities, they select by assessing them from three aspects: the quality of sports facility, the social impact of the sports facility and its types. For quality selection of the sports facility, people mainly consider whether the equipment is complete or not and if fitness fields qualify the merits of the sports facility. During working break days, people consider equipment per capita occupied amount in order to avoid occurrence of insufficient equipment. Besides, there are also some people who consider sports facility locations and surrounding traffic status. Regarding the social impact aspect, the main consideration factors of people include sports facilities' reputation and evaluation, surrounding environment as well as sports facilities grades (district level, country level and city level). However, the type of selection of the sports facility mainly differs according to peoples' expectations of the exercises efficiency. It mainly involves the consideration factors such as leisure, fitness, bodybuilding and weight loss.

According to the analysis above, the hierarchical structure of the influence factors of people's selections of sports facilities can be established as illustrated in Fig. (2):

2) Construct judgment matrix:
Hierarchical structure can clearly reflect relations among elements, but a criterion hierarchy weight in target measuring is not always the same. When one factor occupies more influence factors, the direct influence degree is considered by which each factor affects the factors, it will appear importance inconsistent data and cause errors. This paper adopts comparison between two factors and establishes paired comparison matrix for factor $B$. By taking two factors $B_{i}$ and $B_{j}$ each time, $a_{i j}$ is used to express the influence ratio that $B_{i}$ and $B_{j}$ cover $A$, with all comparison results using matrix $M=\left(a_{i j}\right)_{n \times n} . M$ is the paired comparison judgment matrix between $A-B$, which is called judgment matrix in short. It is clear that if $B_{i}$ and $B_{j}$ to $A$ influence ratio is $a_{i j}$, then $B_{j}$ and $B_{i}$ to $A$ influence ratio should be: $a_{j i}=\frac{1}{a_{i j}}$. The same method is adopted for comparing each $C$ factor, and $B-C$ comparison matrix is established.

For $a_{i j}$ defined value, Saaty and others suggest to quote number $1 \sim 9$ and their reciprocal as scale. Table 3 lists out 1-9 scales definitions.

According to consulted information and data and by making comparison between each factor, judgment matrix can be obtained as follows (listed out in table):

Sports facility selection consideration factor $A$ and sports facility quality $B_{1}$, sports facility social influence $B_{2}$, sports facility types $B_{3}$ comparison matrix $A-B$ are established as shown in the following Table 4 :

Table 5 establishes sports facility quality $B_{1}$ and complete or not $C_{1}$, quality fitness venues $C_{2}$, per capita $C_{3}$, convenient transportation $C_{4}$ comparison matrix $B_{1}-C$ as shown: 


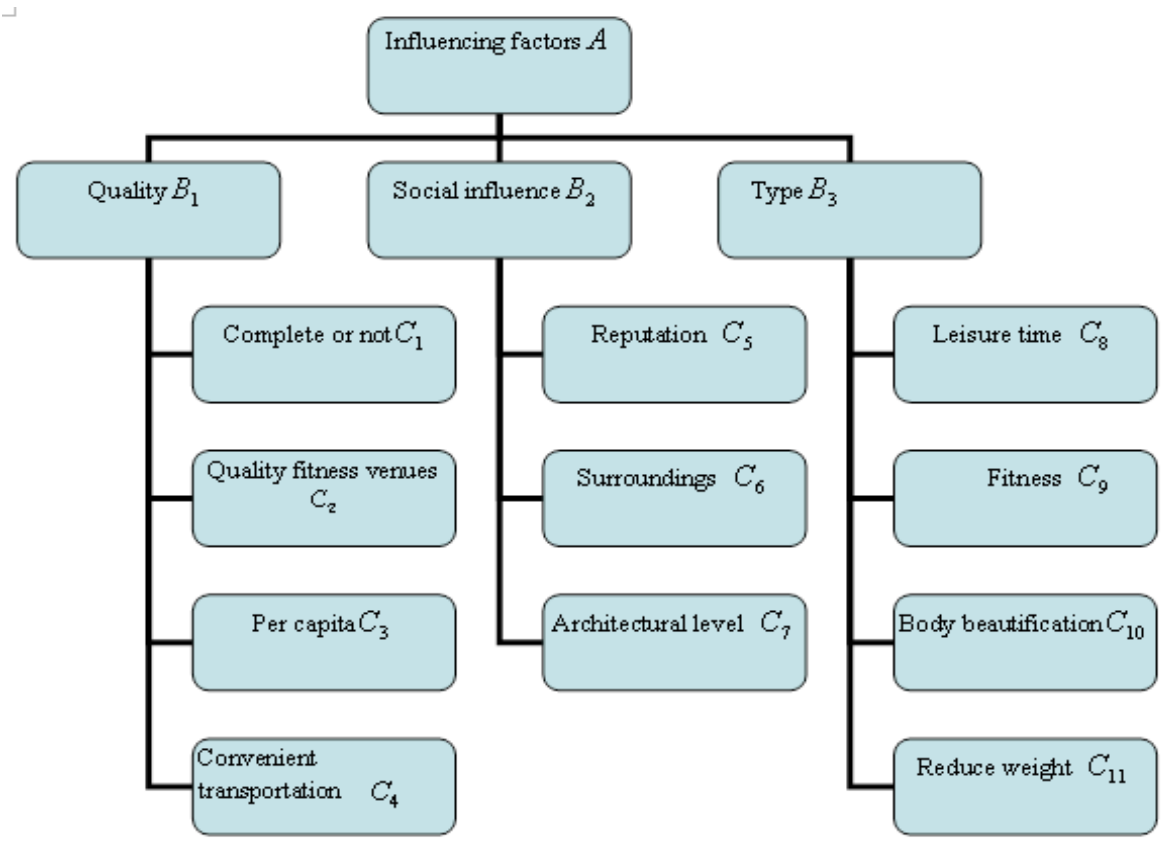

Fig. (2). Sports facility selection influence factors.

Table 3. 1-9 scale $\alpha_{i j}$ definition.

\begin{tabular}{|c|l|}
\hline Scale & \\
\hline \hline 1 & Indicates two factors have equal importance by comparing \\
\hline 3 & Indicates the former is slightly more important than the later by comparing two factors \\
\hline 5 & Indicates the former is obviously more important than the later by comparing two factors \\
\hline 7 & Indicates the former is intensely more important than the later by comparing two factors \\
\hline 9 & Indicates the former is extremely more important than the later by comparing two factors \\
\hline $2,4,6,8$ & Indicates middle value of above adjacent judgment \\
\hline Reciprocal & If importance ratio between element $i$ and element $j$ is $\alpha_{i j}$, then importance ratio between element $j$ and element $i$ is $\alpha_{i j} 1 / \alpha_{i j}$ \\
\hline
\end{tabular}

Table 6 establishes facility social influence $B_{2}$ and reputation $C_{5}$, surroundings $C_{6}$, and architectural level $C_{7}$ comparison matrix $B_{2}-C$ :

Table 7 establishes sports facility type $B_{3}$ and leisure time $C_{8}$, fitness $C_{9}$, body beautification $C_{10}$, and reducing weight $C_{11}$ comparison matrix $B_{3}-C$.

Hierarchical single arrangement and consistency test: Judgment matrix corresponds to maximum feature value $\lambda_{\max }$ feature vector $W$ which is the priority weight of same hierarchy corresponding elements that are relatively important to the last hierarchy element after normalization. This process is called hierarchical single arrangement. Consistency indicator:

$C I=\frac{\lambda-n}{n-1}$

When $C I=0, C, C$ is consistency matrix, the larger the $C I$ the more serious the inconsistency extent $C$. Random consistency indicator $R I$ values are as shown in Table 8 :
The $n \geq 3$ for paired comparison matrix $M$ is called its consistency indicator and same order (referring $n$ as the same) random consistency indicator $R I$ ratio as consistency ratio $C R$, when:

$C R=\frac{C I}{R I}<0.1$

It is considered that $M$ inconsistency extent is within permissible range and it can use its feature vector as weight vector.

By using MATLAB software, each matrix maximum feature value $\lambda_{\max }$ as well as $C I$ are calculated and the consistency is judged whether it passes or not. The results are shown in Table 9:

From Table 9, it is evident that each judgment matrix maximum feature is the same as its matrix orders, and its consistency indicator $C I$ value all is 0 , further indicating each judgment matrix as consistency matrix, so the consistency test is passed. 
Table 4. Comparison matrix $A-B$.

\begin{tabular}{|c|c|c|c|}
\hline $\mathrm{A}$ & $B_{1}$ & $B_{2}$ & $B_{3}$ \\
\hline$B_{1}$ & 1 & $\frac{5}{2}$ & $\frac{5}{6}$ \\
\hline$B_{2}$ & $\frac{2}{5}$ & 1 & $\frac{1}{3}$ \\
\hline$B_{3}$ & $\frac{6}{5}$ & 3 & 1 \\
\hline
\end{tabular}

Table 5. Comparison matrix $B_{1}-C$.

\begin{tabular}{|c|c|c|c|c|}
\hline$B_{1}$ & $C_{1}$ & $C_{2}$ & $C_{3}$ & $C_{4}$ \\
\hline$C_{1}$ & 1 & $\frac{7}{5}$ & $\frac{7}{4}$ & $\frac{7}{2}$ \\
\hline$C_{2}$ & $\frac{5}{7}$ & 1 & $\frac{5}{4}$ & $\frac{5}{2}$ \\
\hline$C_{3}$ & $\frac{4}{7}$ & $\frac{4}{5}$ & 1 & 2 \\
\hline$C_{4}$ & $\frac{2}{7}$ & $\frac{2}{5}$ & $\frac{1}{2}$ & 1 \\
\hline
\end{tabular}

Table 6. Comparison matrix $B_{2}-C$.

\begin{tabular}{|c|c|c|c|}
\hline$B_{2}$ & $C_{5}$ & $C_{6}$ & $C_{7}$ \\
\hline$C_{5}$ & 1 & $\frac{3}{2}$ & 2 \\
\hline$C_{6}$ & $\frac{2}{3}$ & 1 & $\frac{4}{3}$ \\
\hline$C_{7}$ & $\frac{1}{2}$ & $\frac{3}{4}$ & 1 \\
\hline
\end{tabular}

Table 7. Comparison matrix $B_{3}-C$.

\begin{tabular}{|c|c|c|c|c|}
\hline$B_{3}$ & $C_{8}$ & $C_{9}$ & $C_{10}$ & $C_{11}$ \\
\hline$C_{8}$ & 1 & $\frac{4}{7}$ & $\frac{4}{3}$ & $\frac{4}{6}$ \\
\hline$C_{9}$ & $\frac{7}{4}$ & 1 & $\frac{7}{3}$ & $\frac{7}{6}$ \\
\hline$C_{10}$ & $\frac{3}{4}$ & $\frac{3}{7}$ & 1 & $\frac{1}{2}$ \\
\hline$C_{11}$ & $\frac{6}{4}$ & $\frac{6}{7}$ & 2 & 1 \\
\hline
\end{tabular}

Table 8. Random consistency indicator RI.

\begin{tabular}{|c|c|c|c|c|c|c|c|c|c|c|c|}
\hline$n$ & 1 & 2 & 3 & 4 & 5 & 6 & 7 & 8 & 9 & 10 & 11 \\
\hline$R I$ & 0 & 0 & 0.58 & 0.90 & 1.12 & 1.24 & 1.32 & 1.41 & 1.45 & 1.49 & 1.51 \\
\hline
\end{tabular}

Hierarchy $B$ has $B_{1}, B_{2}, B_{3}$ as three influence factors, with their weights on $A$ being $0.385,0.154,0.461$, respectively. The hierarchy $C$ has 11 elements $C_{1}, C_{2}, C_{3}, C_{4}, C_{5}, C_{6}, C_{7}$, $C_{8}, \quad C_{9}, C_{10}, C_{11}$; their weights on hierarchy $B$ are respectively: $0.389,0.278,0.222,0.111,0.461,0.308,0.231$,
$0.2,0.35,0.15,0.3$ (when $C_{i}$ and $B_{j}$ are uncorrelated, $c_{i j}=0$ ). For solving hierarchy $C$ each element total weight on operation efficiency $A$ and for solving hierarchy $C$ each element whole system weight, following formula: 
Table 9. Consistency test result.

\begin{tabular}{|c|c|c|c|c|}
\hline Judgment matrix & Weight vector $W$ & Maximum feature value & CI & $\boldsymbol{R I}$ \\
\hline \hline$A-B$ & $(0.385,0.154,0.461)$ & 3 & 0 & 0.58 \\
\hline$B_{1}-C$ & $(0.389,0.278,0.222,0.111)$ & 4 & 0 & 0.9 \\
\hline$B_{2}-C$ & $(0.461,0.308,0.231)$ & 3 & 0 & 0.58 \\
\hline$B_{3}-C$ & $(0.2,0.35,0.15,0.3)$ & 4 & 0 & 0.9 \\
\hline
\end{tabular}

Table 10. Each element total weight on operation use efficiency.

\begin{tabular}{|c|c|c|c|c|c|c|}
\hline Element & $C_{1}$ & $C_{2}$ & $C_{3}$ & $C_{4}$ & $C_{5}$ & $C_{6}$ \\
\hline Weight & 0.150 & 0.107 & 0.085 & 0.043 & 0.071 \\
\hline Element & $C_{7}$ & $C_{8}$ & $C_{9}$ & $C_{10}$ & $C_{11}$ & 0.047 \\
\hline Weight & 0.036 & 0.093 & 0.161 & 0.069 & 0.138 \\
\hline
\end{tabular}

$c_{i}=\sum_{j=1}^{m} c_{i j} b_{j}, i=1,2, \cdots, 11$

The above formula is utilized for solving hierarchy $C$ each element weight as shown in Table 10:

Weight whole system consistency test:

$C$ hierarchy elements correlated with $B_{j}$ established comparison judgment matrix which passed the consistency test in hierarchical single arrangement. It had solved the consistency indicator $C I(j)$ and its corresponding random consistency indicator $R I(j)$, then $C$ hierarchy whole system random consistency proportion is calculated by:

$$
C R=\frac{\sum_{j=1}^{m} C I(j) b_{j}}{\sum_{j=1}^{m} R I(j) b_{j}}
$$

When $C R<0.10$, the hierarchical whole system result passes consistency test, and the result is relatively precise.

By testing, it is found that $C$ hierarchy correlated with $B_{j}$ elements with $C I(j)$ being0, so the hierarchy whole system random consistency $C R$ passes testing. Table 4 data can be used as each influence factor final weight.

To sum up, it can be stated that the main factors that affect people's selections of sports facilities are whether the facility has fitness efficiency, the equipment is complete or not, and whether it has weight loss efficiency.

\section{CONCLUSION}

By conducting research, it is clear that gross China social public sports facilities obviously do not meet peoples' demandsand equipment utilization rate distribution is extremely imbalanced. Therefore, the nation not only needs to further increase sports construction but also needs to adjust sports facilities layout. It also needs to improve and balance social public sports facility utilization rate. China's current social sports facilities are confronted with a serious situation of imbalanced utilization rate distribution. Therefore, this study suggests the nation to remove sports facilities with lower utilization rate in residential areas and other collective population places. This not only can improve existing resource utilization status, but can also ease high density population area's insufficient sports facilities status.

By factor analysis model result, it has become clear that the main factor of people's sports facilities selection is whether the equipment can fulfil the fitness demand or not. Meanwhile, this factor is combined with the practical factor that China is gradually developing towards a population aging kind of nation; it is clear that main segment of the population that selects fitness facilities are old people. Old people mainly concentrate on running, gate ball, Tai Chi and other small level activities. For the purpose of making transportation convenient for old people, when carrying out sports investment, particular attention should be paid to housing estates sports facilities construction. Weight loss efficiency is also an important consideration factor that prompts people to select these facilities. However, weight losing exercises have higher equipment requirements; though, familiar weight losing exercises in China are Yoga, gym ball and others. Most sports events have higher requirements on fields. Leisure combined exercise is also one of the important consideration factors for people's selection of sports facilities. Nowadays, the most selected leisure activities are mainly shooting, kendo and every kind of ball sport (as volleyball, tennis, table tennis and so on). Each kind of ball sport (as volleyball, tennis, table tennis and so on) can achieve fitness efficiency and meanwhile are also the most attended leisure sports types. All these are indoor sports and are currently the most popular. Furthermore, people's concerns for traffic are relatively secondary. This suggests that nation may as well lay particular stress on 
district level national fitness centre construction. Except for new sports facilities investment construction, maintenance of old sports facilities and improvements in old sports facilities utilization rate can also save resources to a greater extent.

\section{CONFLICT OF INTEREST}

The author confirms that this article content has no conflict of interest.

\section{ACKNOWLEDGEMENTS}

None declared.

\section{REFERENCES}

[1] H. Li, H. Xue, W. Feng, "Sociological analysis of comparison of chinese population with the sports population of chinese," Journal of Xi'an Institute of Physical Education, vol. 24, no. 4, pp. 25-28, 2007.

[2] H. Xiao, Z. Weng, and Y. Chen, "Basic characteristics of social and sports population structures of contemporary china," Journal of Shanghai Physical Education Institute, vol. 29, no. 2, pp. 10-14, 2005.

[3] J. Xue, and J. Wang, "Analysis on development level of competitive sports of eastern china in the "eleventh five-year" period," Bulletin of Sport Science \& Technology, vol. 19, no. 4, pp. 57-59, 2011.

[4] D. Yan, "Development of sports for all under circumstance of building well-off society," Journal of Wuhan Institute of Physical Education, vol. 40, no. 1, pp. 15-19, 2006.

(C) Jianguo Zhu; Licensee Bentham Open

This is an open access article licensed under the terms of the (https://creativecommons.org/licenses/by/4.0/legalcode), which permits unrestricted, noncommercial use, distribution and reproduction in any medium, provided the work is properly cited. 